some time owing to the irregularity of the rent, and at about $1.25 \mathrm{I}$ had to inject one drop here and there. This enabled me to finish the operation, during the whole of which the patient felt no pain. She conversed freely throughout, and 1 had the great advantage of her intelligent obedience, instead of the usual restlessness of a patient under chloroform. Thus, in time cocaine is economical, as while it is taking effect the surgeon can be attending to matters which, with chloroform or ether, must be seen to beforehand; and there is also a saving in money, as no assistant is required, and the actual cost will bear comparison with that of chloroform. This operation cost me twenty minims of a 20 per cent. solution, or four grains, which, at $7 \frac{3}{4} d$, a grain (the present price), comes to $7 \bar{d}$.

I have also performed circumcision on a young man at a cost of five minims, or one grain, $=1 \frac{3}{4} d$. The operation including the arrangement of the pationt and instruments, occupied twenty minutes only. Of course, in this case the original injection of the cocaine-one drop of a 20 per cent. solution into four separate parts of the prepuce-was painful, but if a very fine needle is used the discomfort is trivial.

Another advantage of cocaine (though a decided disadvantage sometimes) is that, whereas cedema coming on after an operation often strains the stitches more than can well be calculated upon or allowed for at the time, the injection of the drug rapidly induces this swelling; and the tension put upon the sutures in tying them will be found suitable to the subsequent condition of the parts.

I look upon cocaine as a special boon to the general practitioner who has to work single-handed or with inefficient assistance.

I am, Sir, yours faithfully,

Tottenham, May 3rd, 1886. A. Ogier WARD, M.B. \&c.

\section{"THE PRIZE SYSTEM."}

To the Editor of THE LANCET.

SIR,-Your correspondent, “F.R.C.S.," sends you an interesting extract showing Sir Benjamin Brodie's opinion of giving prizes to medical students. In his autobiography he is still more emphatic, and the opinion of a surgeon so successful in the highest sense of the term must carry weight. He says: "I had leisure to make my own observations, to think and reflect. Nor was this style of education peculiar to myself. I remember when Mr. Abernethy complained that Lawrence would not attend lectures. My friends and contemporaries, Jeffreys and Lawrence, took the same course; and so it had been with Nicolson, who was some years in advance of us. I can easily conceive that, if $T$ had been compelled to sit, on the benches of a theatre four or five hours daily, or tempted to compete for prizes as students are, and to get crammed for various examinations, my position in life afterwards would have been very different from what it has been in reality."

I am, Sir, yours \&c.,

Wimpole-street, May 2nd, 1886. G. BuCKsToN BRowNE.

\section{TRAINED NURSES IN INFECTIOUS CASES. To the Editor of THE LANCET.}

SrR,-The now numerous institutions for the supply of trained private nurses meet a great public want, and I believe that upon the whole they are well managed and deserve the success which they have attained. Having recently had occasion to make inquiries as to the precautions observed by some of them with regard to infectious cases, I find that there is a considerable difference in their practice in this respect. The rules of the Nottingham and Notts Nursing Association-to quote an example-require that a nurse upon leaving an infectious case shall not only undergo a thorough disinfection of person and clothing, but shall remain in quarantine for two weeks before taking charge of another patient. This is as it should be; and similar rules are enforced at Sheffield, and no doubt at many, if not most, other centres. Recent experiments tend to make us very sceptical as to the entire trustworthiness of many of the ordinary processes of disinfection, and in view of the possibility of a nurse herself acquiring the disease or conveying infection in spite of disinfectants, the period of quarantine must be regarded as a wise and necessary precaution. It is, therefore, with some surprise that I find it ignored by at least one institution, nurses being sent, after ordinary disinfection, to new patients immediately after returning from infectious cases.

In one instance which came to my knowledge recently, \& nurse returned from a fatal case of diphtheria and was next day sent to take charge of a case at a distance. This second case also subsequently proved to be diphtheria, and ended fatally. The nurse, being questioned as to the nature of the illness of her former patient, asserted that it was "croup." The diagnosis of diphtheria was made within a few hours after the arrival of the nurse, so that it seems highly improbable that the infection was brought by her, but the possibility of this led to inquiries, and thus to the discovery of the facts already stated. How far other nursing institutions share this custom I cannot say, but such laxity is a source of danger, and is unworthy of an institution which appears to enjoy the confidence of the medical profession and the public. Most practitioners would, I think, hesitate knowingly to expose their patients to the risk of being attended by a nurse fresh from an infectious case, especially where they have no means of judging of the efficacy of the safeguards adopted. In the absence of any provision for obtaining the consent of the responsible medical attendant to such a course, it is incumbent upon the managers of nursing institutions to recognise their full responsibility and to take all reasonable measures of precaution. I am, Sir, yours faithfully,

May 3 rd, 1886.

B. A. WhItELEGGe, M.D., B.Sc., Medical Officer of Health, Nottingham.

\section{"ON THE RATIONAL TREATMENT OF HYDROPHOBIA,"}

To the Editor of THA LANCET.

SIR,- - The medical profession will be under great obligation to Mr. Richards for the timely warning he has given of the dangerous or fatal dose of the snake poison which was advocated in my paper on the Rational Method of Treatment of Hydrophobia in your issue of January last. Unfortunately for my critic, he has set up a phantom to enjoy the selfsatisfaction of seeing it knocked down by his missiles, for he ascribes to me a dose which I am innocent of. In my paper referred to above I suggested one drop of the poison, which my critic has transformed into one grain, which is equivalent to three minims or five or six drops of the liquid poison. Thus, having magnified my dose five times, like the true valiant knight of the fable he has hurled down his weapons of assault for my demolition.

My personal thanks are due to him also for the gratuitous offer of enlightening my knowledge on woorara having been used in hydrophobia, but I would not injure his self-esteem by assuring him that I had the fullest consciousness of the fact. Then, in a spirit of nonchalance as it were, he kindly passed over "the crude and incorrect physiological action of the poison," as enunciated in my paper, to attack the most important and vulnerable portion he found in it-the dose. Like other critics of his class, he evidently rejoices in finding fault with the tail of a horse to the exclusion of its body and limbs. But perhaps Mr. Richards, who is superintendent of coolies in Goalunda, is not aware of the fact that in diseased states of the system there is a toleration for medicines with opposite physiological actions. Thus, in delirium tremens and diarrhoea a quantity of opium will be admissible which will be poison in a healthy state. Taking, therefore, my recommendation of dose as one drop and in a diseased condition of the body, I do not think I have overshot the mark and suggested to the profession a fatal remedy, with which I have been charged by him.

I am, Sir, yours truly,

$\begin{array}{ll}\text { Burdwan, April 13th, } 1886 . & \text { G. C. Ror, M.D., F.R.C.S }\end{array}$

\section{LIVERPOOL.}

\section{(From our own Correspondent.)}

THE SCHOOL OF MEDICINE.

THe Summer Session of the Medical Faculty of the Liverpool University College commenced on the 3rd inst. The staff of lecturers has been augmented by the recent election of Dr. Edward William Hope, assistant medical officer of health to the City and Port of Liverpool, as lecturer on 